\title{
Involvement of Toll-Like Receptor 2 and Pro-Apoptotic Signaling Pathways in Bone Remodeling in Osteomyelitis
}

\author{
Qianbo Chen ${ }^{a, b, c, d}$ Tianyong Hou ${ }^{a, b, c, d}$ Fei Luo ${ }^{a, b, c, d}$ Xuehui Wu ${ }^{a, b, c, d}$ Zhao Xie \\ Jianzhong $X^{a, b, c, d}$
}

\begin{abstract}
aNational and Local United Engineering laboratory of Tissue Engineering, Department of Orthopaedics, Southwest Hospital, the Third Military Medical University, ${ }^{b}$ Key Laboratory of Bone Tissue Engineering in PLA, the Third Military Medical University, 'Laboratory of Tissue Engineering in Chongqing City, ${ }^{d}$ Center of Regenetive and Reconstructive Engineering Technology in Chongqing City, Chongqing, China
\end{abstract}

\section{Key Words}

Toll-like receptor 2 -Staphylococcus aureus $•$ Osteomyelitis $\bullet \mathrm{c}$-Jun $\mathbf{N}$-terminal kinase pathway

\begin{abstract}
Background and Aims: Osteomyelitis is a common manifestation of invasive Staphylococcus aureus infection characterized by bone loss and destruction. We investigated the role of tolllike receptor 2 (TLR2) in bacterial recognition and clearance in response to infection with an osteomyelitis isolate of S. aureus. Methods: Apoptosis was assessed in the osteoblastic cell line MC3T3-E1 by Annexin V-FITC/PI staining and flow cytometry. The expression of TLR2 and apoptosis-related and mitogen-activated protein kinase pathway proteins was assessed by qRT-PCR and western blotting. Alkaline phosphatase (ALP) activity and calcium deposition were assessed by ALP activity assay and Alizarin red staining. Results: S. aureus induced apoptosis, upregulated TLR2 expression, and activated mitogen-activated protein kinase pathways in a time dependent manner. Inhibition of the c-Jun N-terminal kinase (JNK) pathway downregulated TLR2 and suppressed the $S$. aureus induced activation of pro-apoptotic pathways. Short-hairpin RNA mediated silencing of TLR2 reversed S. aureus induced apoptosis and decrease in ALP activity and calcium deposition, and inhibition of JNK had a similar effect. Conclusion: We showed that osteoblast apoptosis and osteogenic differentiation in response to bacterial invasion are dependent on TLR2 expression and JNK activation, suggesting novel potential therapeutic targets for the treatment of osteomyelitis.
\end{abstract}

Copyright (C 2014 S. Karger AG, Basel 


\section{Cellular Physiology and Biochemistry}

Cell Physiol Biochem 2014;34:1890-1900

\begin{tabular}{l|l}
\hline DOI: $10.1159 / 000366387$ & (C) 2014 S. Karger AG, Basel
\end{tabular}

www.karger.com/cpb

Chen et al.: TLR2 Knockdown Attenuates S. Aureus Effects in Osteomyelitis

\section{Introduction}

Osteomyelitis is an inflammation of the bone caused by an invading organism, and it is characterized by progressive bone destruction and bone neoformation [1,2]. Bone remodeling is necessary for skeletal growth and the maintenance of bone structure, and it depends on the balance between bone resorption and formation [3]. The resorption of bone by osteoclasts is followed by new bone formation by osteoblasts in a complex cascade of events involving several factors [4]. The maturation of osteoblasts is characterized by the expression of alkaline phosphatase (ALP), which is important for bone matrix deposition and mineralization, whereas differentiated mature osteoblasts produce osteocalcin and osteopontin to regulate matrix mineralization $[5,6]$.

Although osteolytic diseases including osteomyelitis are associated with bacterial infections, the precise mechanisms by which bacteria induce bone loss remain unclear. Among the bacterial species isolated from osteomyelitis, Staphylococcus aureus (S. aureus) is the most common organism, accounting for approximately $80 \%$ of all osteomyelitis cases [7] . S. aureus is a gram positive bacterium that lives in the microflora of the skin and mucous membranes of humans and animals [8]. It is an opportunistic pathogen capable of producing a large number of virulence factors that mediate its attachment to host cells. The infection of bone tissue alters the bone remodeling process regulated by osteoblasts and osteoclasts $[4,9]$. S. aureus is internalized by phagocytic vesicles in osteoblasts, protecting the bacteria from immune or antibiotic attack and leading to osteoblast apoptosis and the prevention of new bone formation $[10,11]$.

Host defense against microbial pathogens is mediated by innate and acquired immune mechanisms, and Toll-like receptors (TLRs) have been recognized as a system of innate immunity for the detection of invading microbes $[12,13]$. Mammalian TLRs comprise a large family of at least 11 members, among which TLR1-9 are conserved between the human and mouse [14]. TLR2 is essential for the recognition of microbial components, in particular lipoproteins/lipopeptides, peptidoglycan and lipoteichoic acid from Gram-positive bacteria $[15,16]$. Recognition of microbial components by TLRs triggers the activation of signal transduction pathways that control the expression of genes regulating immune responses.

The family of mitogen-activated protein kinases (MAPKs) includes three distinct subfamilies that control many physiological processes via a phosphorelay system based on mutual phosphorylation and activation [17]. Extracellular signal-regulated kinases (ERKs) control cell division, c-Jun N-terminal kinases (JNK) are regulators of transcription, and p38 MAPKs are activated by inflammatory cytokines and environmental stresses $[18,19]$. The JNK cascade, also referred to as the stress-activated signaling pathway, has been mostly implicated in mediating the apoptotic response of cells to pro-inflammatory cytokines and genotoxic and environmental stresses [20]. However, JNK activation, which is mediated by dual phosphorylation on a Thr-Pro-Tyr motif, has also been implicated in cell proliferation, survival and differentiation. The apparently antagonistic functions of JNK activation have been attributed to differences in signal intensity and duration, as transient activation of JNK promotes cell survival, whereas prolonged JNK activation induces apoptosis [21].

In the present study, we investigated the contribution of TLR2 to bacterial clearance in response to $S$. aureus infection in an osteoblastic cell line. We found that $S$. aureus induced apoptosis in association with the upregulation of TLR2 through a mechanism dependent on the activity of the pro-apoptotic JNK pathway. Silencing of TLR2 suppressed the effects of $S$. aureus infection on apoptosis and the calcification of osteoblasts via a mechanism involving the JNK pathway, confirming the role of TLR2 and suggesting a possible mechanism underlying bone loss in response to bacterial infection in osteomyelitis.

\section{Materials and Methods}

Bacterial culture conditions

Staphylococcus aureus 6850 (ATCC53657, wild-type isolate from osteomyelitis) was grown in tryptic soy broth (TBS) at $37^{\circ} \mathrm{C}$ with shaking. After harvesting, bacteria were washed by centrifugation at $15,000 \mathrm{~g}$ 


\section{Cellular Physiology and Biochemistry}

Cell Physiol Biochem 2014;34:1890-1900

DOI: $10.1159 / 000366387$

Publisned online: November 21, 2014

c) 2014 S. Karger AG, Basel

www.karger.com/cpb

Chen et al.: TLR2 Knockdown Attenuates S. Aureus Effects in Osteomyelitis

for $5 \mathrm{~min}$, resuspended in phosphate buffered saline (PBS) and the suspensions adjusted to $1 \times 10^{9} \mathrm{cells} / \mathrm{ml}$. Bacterial supernatants were prepared by culturing $S$. aureus in TBS for $12-14 \mathrm{~h}$, followed by centrifugation for $10 \mathrm{~min}$ at $3000 \mathrm{~g}$ and filtration of supernatants through a $0.22 \mu \mathrm{m}$ filter.

\section{Cell culture and treatment}

The murine pre-osteoblastic cell line MC3T3-E1 was obtained from the American Type Culture Collection and cultured in standard tissue culture flasks in $\alpha$-MEM medium (Invitrogen Corporation, Carlsbad, CA, USA) supplemented with 10\% FBS (Gibco, Life technologies, Alcobendas, Spain), 2\% penicillin/ streptomycin solution (Sigma-Aldrich, St Louis, MO, USA) and 1\% L-glutamine (Sigma-Aldrich). For cell infection, cells were incubated with prepared bacterial suspensions at a multiplicity of infection (MOI) of 100. Infected cells were preincubated for $30 \mathrm{~min}$ at room temperature to allow sedimentation of bacteria and then shifted to $37^{\circ} \mathrm{C}$ for assays. For gene expression analysis and cell apoptosis analysis, the infected cells were incubated for the indicated time periods $(6,12,24$ and $48 \mathrm{~h})$ with uninfected cells incubated for $48 \mathrm{~h}$ as controls. For JNK pathway experiments, MC3T3-E1 cells were pretreated with $25 \mu \mathrm{M}$ of the JNK inhibitor SP600125 (Sigma Aldrich) or $20 \mu \mathrm{M}$ of the ERK inhibitor PD98059 (Sigma Aldrich) or an equal volume of $0.5 \%(\mathrm{v} / \mathrm{v}$ ) DMSO for $1 \mathrm{~h}$ before infection.

\section{Assessment of apoptosis}

MC3T3-E1 cells treated as indicated were plated in six-well plates, incubated for the indicated times and apoptosis was determined using an Annexin V-FITC apoptosis detection kit according to the manufacturer's instructions (Sigma Aldrich). Briefly, cells were trypsinized for 1 min, resuspended in $100 \mu \mathrm{l}$ of $1 \times$ binding buffer to a concentration of $10^{6}$ cells $/ \mathrm{ml}$, transferred to a tube containing $5 \mu \mathrm{l}$ Annexin V/FITC and $10 \mu \mathrm{l}$ propidium iodide (PI) and incubated for $30 \mathrm{~min}$ in the dark at room temperature. Flow cytometry analysis was performed after addition of $400 \mu \mathrm{l}$ of $1 \times$ binding buffer in a FACScalibur flow cytometer (Becton Dickinson, San Jose, CA, USA) and analyzed using Cell Quest software. Cells in the lower right quadrant represented apoptosis and in the upper right quadrant represented necrosis or post apoptotic necrosis.

\section{Western blotting}

For western blot analysis, cultured cells were washed with cold PBS, lysed in ice-cold lysis buffer (50 $\mathrm{mmol} / \mathrm{L}$ Tris-HCl, $150 \mathrm{mmol} / \mathrm{L} \mathrm{NaCl}, 1 \mathrm{mmol} / \mathrm{L}$ EGTA, $1 \mathrm{mmol} / \mathrm{L}$ EDTA, $20 \mathrm{mmol} / \mathrm{l} \mathrm{NaF}, 100 \mathrm{mmol} / \mathrm{L} \mathrm{Na}_{3} \mathrm{VO}_{4}$, $0.5 \%$ NP40, 1\% Triton X-100, $1 \mathrm{mmol} / \mathrm{L}$ PMSF and a protease inhibitor cocktail) and the lysate was cleared by centrifugation at $14,000 \mathrm{~g}$ for $15 \mathrm{~min}$ at $4^{\circ} \mathrm{C}$. Aliquots containing 25-40 $\mu \mathrm{g}$ of protein were resolved in 8-12\% polyacrylamide gels and transferred to nitrocellulose membranes. Blots were blocked in blocking buffer (TBS containing 5\% nonfat dry milk and 1\% Tween 20 ) for $1 \mathrm{~h}$ at room temperature, and incubated in the indicated primary antibodies in blocking buffer for $2 \mathrm{~h}$ at room temperature or overnight at $4^{\circ} \mathrm{C}$. After incubation in the appropriate secondary antibodies, blots were developed by enhanced chemiluminescence (Amersham Life Science) and autoradiography. Primary antibodies (Abcam) and their dilutions were as follows: anti-active caspase 3 (1/200), anti-Bax (1/1000), anti-Bcl-2 (1/500), anti-TLR2 (1/200), anti-Erk1 (pT202/pY204) + Erk2 (pT185/pY187) (1/5000), anti-ERK1 + ERK2 (1/1000), anti-JNK1+JNK2 (pT183 + pY185) (1/1000), anti-JNK1/2 (1/500), anti-c-Jun (phospho S63) (1/5000), anti-c-Jun (1/1000), anti$\beta$-actin (1/2500). Secondary antibodies used were as follows: goat polyclonal anti-rabbit IgG-H\&L-PreAdsorbed (HRP) at $1 / 2000$ dilution. $\beta$-actin served as loading control.

\section{Quantitative real-time PCR}

The mRNA expression of TLR2 was detected by quantitative real-time PCR. Cells were plated in six-well plates, cultured overnight and total RNA was extracted using the Trizol reagent (Invitrogen) according to the manufacturer's instructions. RNA integrity and concentration were determined by spectrophotometry, with a 260/280 ratio $\geq 1.8$ considered acceptable. First-strand cDNA was synthesized using a reverse transcription system (Promega, Madison, WI, USA). The following primers were used for amplification from first-strand cDNA: TLR2 forward, $5^{\prime}$-CAC TGG GGG TAA CAT CGC TT- $3^{\prime}$ and reverse, $5^{\prime}$-GCT GAC TTC ATC TAC GGG CA-3'; GAPDH forward, 5'-GTG ATG GGT GTG AAC CAC GA-3' and reverse, 5'-GTC AGA TCC ACG ACG GAC AC-3'. Quantification of transcripts was performed using the ABI PRISM 7500 sequence detection system (Applied Biosystems) with the DyNAmo SYBR Green qPCR kit. PCR parameters were as follows: $95^{\circ} \mathrm{C}$ for 10 min, and then 38 amplification cycles of $95^{\circ} \mathrm{C}$ for $15 \mathrm{~s}, 60^{\circ} \mathrm{C}$ for $1 \mathrm{~min}$. The threshold cycle (Ct) was defined 


\section{Cellular Physiology and Biochemistry}

Cell Physiol Biochem 2014;34:1890-1900

\begin{tabular}{l|l}
\hline DOI: $10.1159 / 000366387$ & (C) 2014 S. Karger AG, Basel
\end{tabular}

www.karger.com/cpb

Chen et al.: TLR2 Knockdown Attenuates S. Aureus Effects in Osteomyelitis

as the fractional cycle number at which the fluorescence passes the fixed threshold and quantification of mRNA abundance was performed using the $2^{-\Delta \Delta \mathrm{Ct}}$ method [22], using GAPDH mRNA expression level for normalization.

Lentivirus-based short hairpin RNA (shRNA) transfection

For genome-wide production of lentiviral particles, HEK293 cells were cultured for one day before transfection with $6 \mu \mathrm{g}$ of the lentivirus vector pLKO.5 (Sigma) encoding shRNA targeting TLR2. The following shRNA sequences were used: scrambled shRNA, GTACAGAGATCACATACCA; TLR2-shRNA1, GATAATCACCTATCTAGTTTA; TLR2-shRNA2, CACTATCCGGAGGTTGCATAT. The recombinant lentivirus was produced by cotransfection of HEK293 cells with two helper vectors, pCMV and pMD.G, and the target vector pLKO.5-puro-shRNA. MC3T3-E1 cells were then infected with recombinant lentivirus for $48 \mathrm{~h}$.

\section{Measurement of alkaline phosphatase activity}

For measurement of alkaline phosphatase activity, MC3T3-E1 cells were treated as indicated, lysed in $1 \mathrm{ml}$ of lysis buffer containing a chromogenic substrate $(0.1 \mathrm{M} \mathrm{Na}$ acetate, $2 \%$ Triton X-100 and $10 \mathrm{mM}$ p-nitrophenyl phosphate) and incubated in the dark for $1 \mathrm{~h}$ at $37^{\circ} \mathrm{C}$. The reaction was stopped with $0.3 \mathrm{M}$ $\mathrm{NaOH}$, and absorbance was measured in triplicate wells at $\mathrm{A}_{405} \mathrm{~nm}$ in a microplate reader.

\section{Alizarin red staining}

MC3T3-E1 cells treated as indicated were washed, fixed in 4\% paraformaldehyde in PBS for 15 min, and stained with $2 \%$ Alizarin red $\mathrm{S}$ in $\mathrm{H}_{2} \mathrm{O}$ for $30 \mathrm{~min}$ at room temperature. After staining, cultures were washed and absorbance was read at $540 \mathrm{~nm}$.

\section{Statistical analyses}

Data are representative of at least 3 independent experiments. Results are expressed as mean \pm standard deviation. Data were analyzed by one-way ANOVA (SPSS 17.0) and values with $\mathrm{P}<0.05$ were considered statistically significant.

\section{Results}

\section{S. aureus induces apoptosis in an osteoblast cell line}

Murine MC3T3-E1 cells were infected with S. aureus for 6, 12, 24 and $48 \mathrm{~h}$ and apoptosis was determined by Annexin V-FITC/PI double staining. The results of flow cytometric analysis showed that $S$. aureus induced apoptosis in a time dependent manner, with an increase in the percentage of apoptotic cells from approximately $2.5 \%$ in the untreated controls to $45 \%$ in S. aureus infected cells at $48 \mathrm{~h}(\mathrm{p}<0.05$ at $12 \mathrm{~h}$ and $\mathrm{p}<0.01$ at 24 and $48 \mathrm{~h}$ compared to the untreated controls) (Fig. 1A). The effect of $S$. aureus on the induction of apoptosis was confirmed by western blot analysis of apoptosis markers, which showed that $S$. aureus infection significantly increased the levels of cleaved caspase- 3 and Bax and decreased the levels of the anti-apoptotic protein Bcl-2 in a time dependent manner (Fig. 1B).

\section{S. aureus induction of TLR2 is associated with mitogen activated protein kinase pathway} activation

To examine the effect of $S$. aureus on innate immunity, the levels of TLR2 were examined in MC3T3-E1 cells infected with $S$. aureus for $6,12,24$ and $48 \mathrm{~h}$ and normalized to the levels of GAPDH. The results showed a significant time dependent upregulation of TLR2 expression at the mRNA and protein levels (Fig. 2A). Stable expression of GAPDH mRNA in MC3T3-E1 cells infected with $S$. aureus was demonstrated previously [23].

Because mitogen-activated protein kinase (MAPK) signaling pathways play critical roles in regulating cell proliferation and survival in response to stress, the effect of $S$. aureus on the activation of MAPK pathway members was examined in MC3T3-E1 cells. The results showed that $S$. aureus infection promoted the phosphorylation of ERK, JNK and the JNK-dependent transcription factor c-Jun in a time dependent manner (Fig. 2C). Quantification of protein 
A

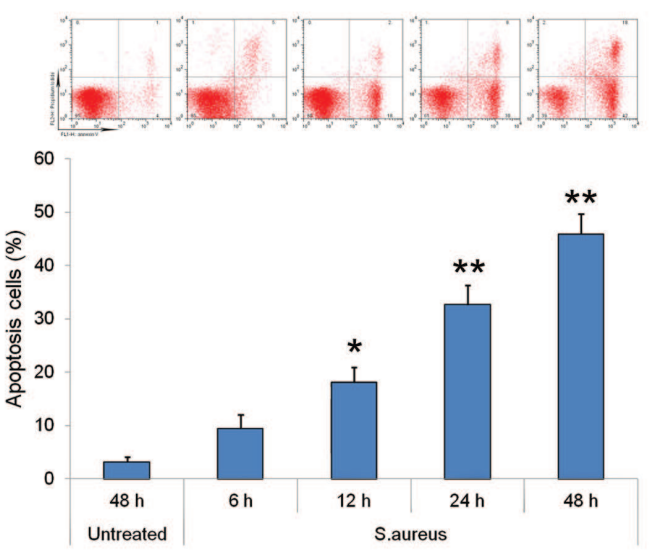

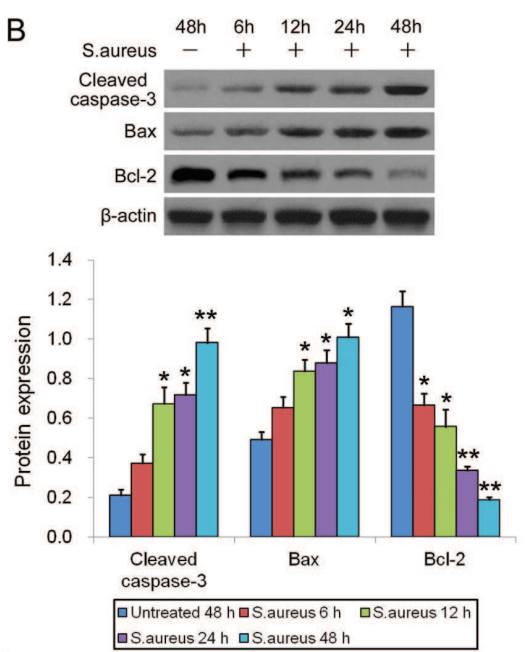

Fig. 1. S. aureus induced apoptosis in MC3T3-E1 cells. Cells were treated with $S$. aureus and incubated for 6, 12, 24, and $48 \mathrm{~h}$, with untreated cells cultured for $48 \mathrm{~h}$ as controls. (A) Apoptosis was determined by Annexin V-FITC/PI double staining and flow cytometry. (B) Protein levels of cleaved caspase-3, Bax and Bcl-2 were analyzed by western blotting and quantified by densitometry with normalization to the levels of $\beta$-actin. ${ }^{*} \mathrm{p}<0.05,{ }^{* *} \mathrm{p}<0.01$ compared with untreated cells.

expression by densitometry showed that the increase in the levels of these phosphorylated proteins was statistically significant $(p<0.05$ and $p<0.01$ at the indicated time points in Fig. 2C).

S. aureus induced apoptosis is dependent on mitogen activated protein kinase signaling

Pre-treatment of cells with the JNK inhibitor SP600125 or the ERK inhibitor PD98059 significantly suppressed the $S$. aureus induced phosphorylation of JNK, c-Jun (Fig. 3A) and ERK (Fig. 3B, p $<0.05$ all). Furthermore, inhibition of JNK and ERK phosphorylation by SP600125 and PD98059, respectively, significantly suppressed $S$. aureus induced apoptosis in MC3T3-E1 cells (Fig. 3C, p<0.05), confirming the involvement of MAPK signaling in the osteoblast response to $S$. aureus infection.

\section{Silencing of TLR2 suppressed the effects of S. aureus infection}

To further examine the role of the TLR2 pathway in the defense against $S$. aureus infection in osteoblasts, the effects of shRNA silencing of TLR2 on apoptosis and calcium deposition were examined. Two different shRNA constructs showed efficient silencing of TLR2 in MC3T3-E1 cells, reducing mRNA levels to approximately $25 \%$ and $30 \%$ of the scrambled shRNA control ( $\mathrm{p}<0.01$ ) (Fig. 4A). A similar effect was observed at the protein level as determined by western blotting, with an approximately 4- and 3.5-fold downregulation of TLR2 expression induced by shRNA 1 and shRNA2, respectively $(\mathrm{p}<0.01)$ (Fig. 4B). Silencing of TLR2 significantly abrogated the $S$. aureus induced phosphorylation of ERK, JNK (approximately 50\%) and c-Jun (approximately 60\%), indicating that the effects of S. aureus mediated by MAPK pathway activation are dependent on TLR2 expression (Fig. 4C).

S. aureus induced osteoblast apoptosis and osteogenic differentiation depend on TLR2 expression and JNK activation

The effect of TLR2 silencing and inhibition of JNK signaling on apoptosis induced by $S$. aureus infection was examined by Annexin V-FITC/PI double staining and flow cytometry, which showed that pretreatment with the JNK inhibitor SP600125 significantly inhibited S. aureus induced apoptosis (Fig. 5A). Silencing of TLR2 had a similar effect, significantly 


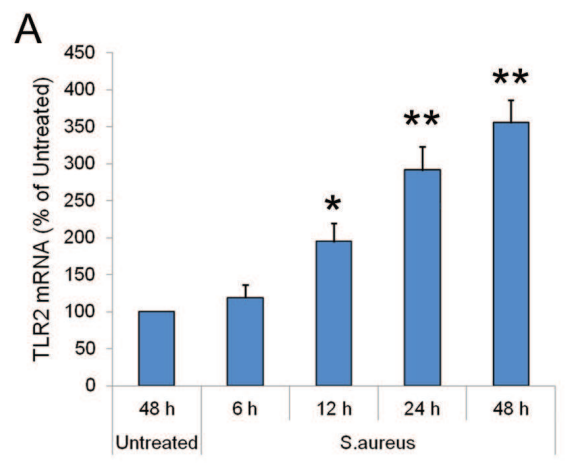

B
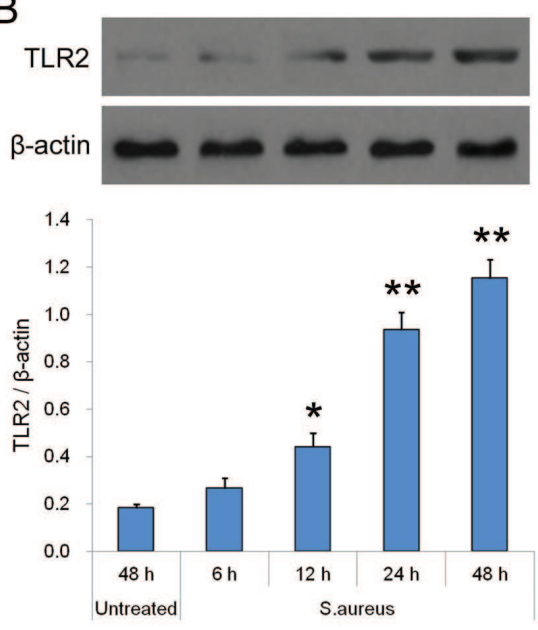

C

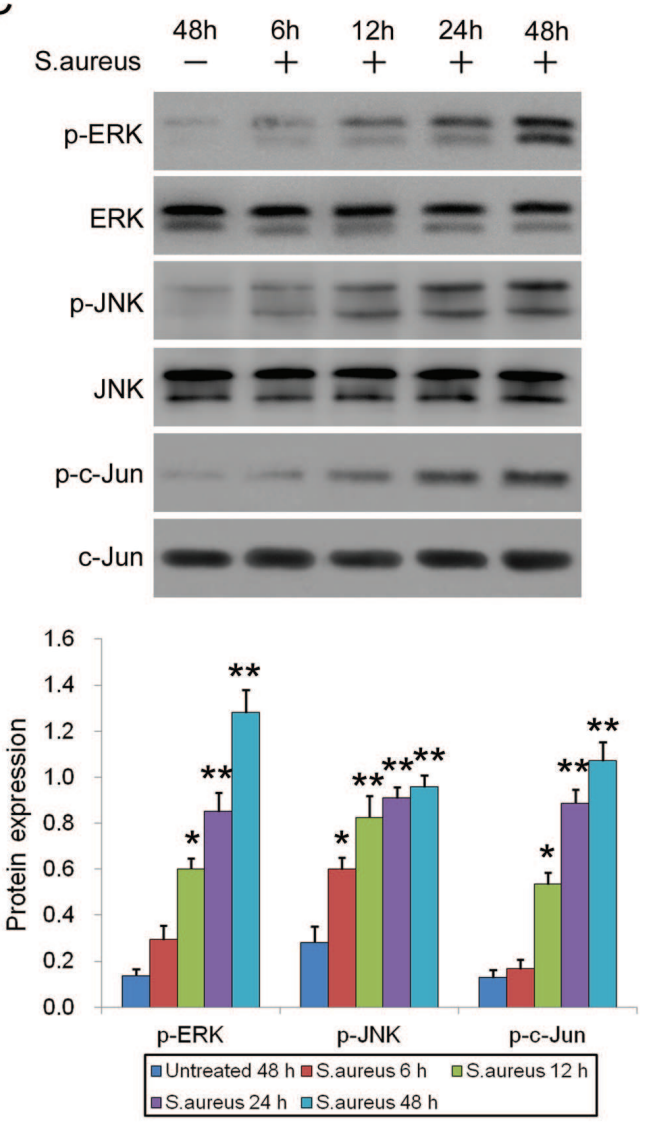

Fig. 2. S. aureus induced TLR2 expression and activation of the JNK pathway. MC3T3-E1 cells were treated with $S$. aureus and incubated for the indicated times with untreated cells cultured for $48 \mathrm{~h}$ as controls. (A) TLR2 mRNA expression was measured by qRT-PCR, normalized to GAPDH expression and the results were expressed as fold-change relative to the untreated group. (B) TLR2 protein expression was detected by western blotting and quantified by densitometry with normalization to the levels of $\beta$-actin. Histograms, relative densities of the bands normalized to b-actin. (C) Protein levels of p-ERK, p-JNK, and p-c-Jun were analyzed by western blotting, quantified by densitometry and normalized to the corresponding unphosphorylated protein. ${ }^{*} \mathrm{p}<0.05,{ }^{* *} \mathrm{p}<0.01$ compared with the untreated cells.

suppressing S. aureus induced apoptosis ( $\mathrm{p}<0.05$ ), and treatment of cells with both shTLR2 and SP600125 only slightly potentiated this effect in MC3T3-E1 cells.

To examine the effect of $S$. aureus infection on osteoblast mineralization, the activity of ALP, a crucial enzyme for bone mineralization, and calcium deposition were measured in MC3T3-E1 cells treated with or without shRNA against TLR2 and pretreated or not with SP600125. After 7 days of $S$. aureus infection, ALP activity was significantly decreased in DMSO treated cells, whereas JNK inhibition significantly reversed this effect $(\mathrm{p}<0.05)$ (Fig. 5B). Silencing of TLR2 had a similar effect, significantly suppressing the $S$. aureus induced reduction in ALP activity ( $\mathrm{p}<0.05)$, whereas the addition of SP600125 did not have an additive effect. Assessment of calcium deposition by Alizarin red staining supported these results and showed that calcium deposition was significantly inhibited by $S$. aureus infection and pretreatment with SP600125 or TLR2 silencing significantly reversed this effect (Fig. 5C). 


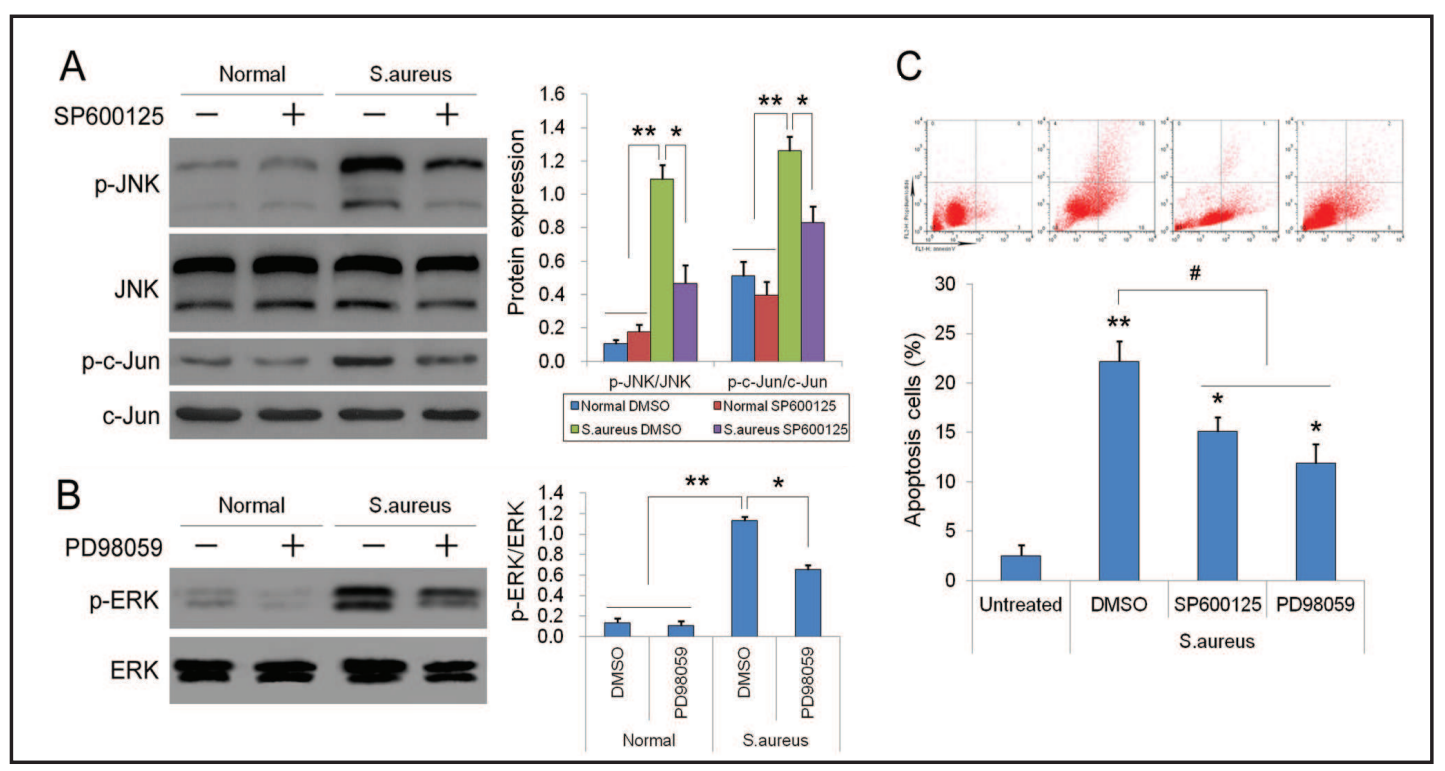

Fig. 3. The effects of $S$. aureus infection are mediated by the JNK pathway. MC3T3-E1 cells were pretreated with $25 \mu \mathrm{M}$ of SP 600125 or $20 \mu \mathrm{M}$ of PD98059 or an equal volume of $0.5 \%$ (v/v) DMSO for $1 \mathrm{~h}$ and cultured for $24 \mathrm{~h}$ or infected with S. aureus at $100 \mathrm{MOI}$ and incubated for $24 \mathrm{~h}$. (A-B) The levels of p-JNK, p-c-Jun (A) and p-ERK (B) were analyzed by western blotting, quantified by densitometry and normalized to the expression of the corresponding unphosphorylated protein. ${ }^{*} \mathrm{p}<0.05$, ${ }^{* *} \mathrm{p}<0.01$. (C) Apoptosis was determined by Annexin V-FITC/PI double staining and flow cytometry. ${ }^{*} \mathrm{p}<0.05,{ }^{* *} \mathrm{p}<0.01$ compared with untreated cells. \#p<0.05.

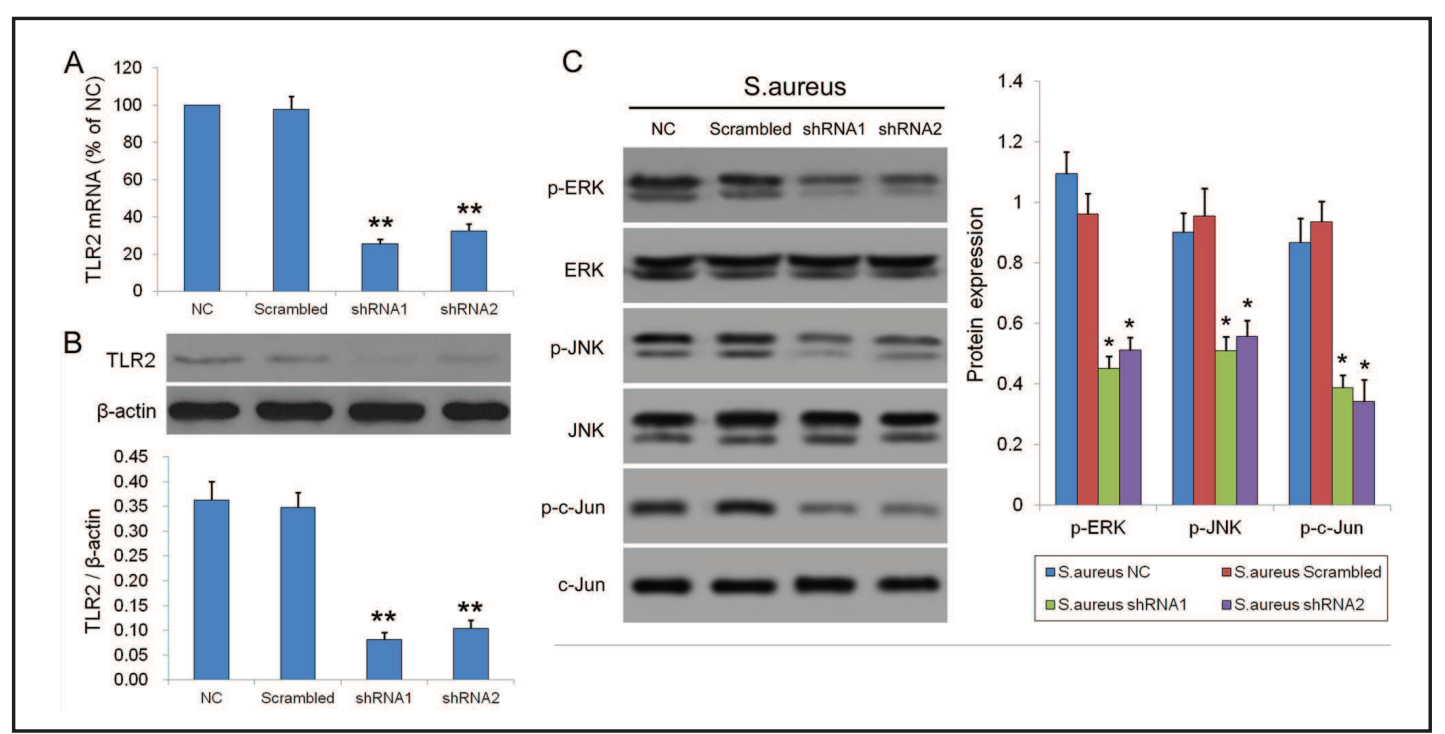

Fig. 4. Short hairpin RNA (shRNA) silencing of TLR2. MC3T3-E1 cells were infected with lentiviral vectors carrying shRNAs targeting TLR2 (shRNA1 or shRNA2) for $48 \mathrm{~h}$ and uninfected cells (NC) or cells infected with scrambled shRNA lentivirus served as controls. (A) TLR2 mRNA was detected by qRT-PCR, normalized to GAPDH expression and depicted as fold-change relative to the untreated group. (B) TLR2 protein levels were analyzed by western blotting and quantified by densitometry with normalization to the levels of $\beta$-actin. ${ }^{* *} \mathrm{p}<0.01$ compared with the NC group. (C) The indicated cells were infected with S. aureus at 100 MOI and incubated for $24 \mathrm{~h}$. Protein levels of p-ERK, p-JNK, and p-c-Jun were analyzed by western blotting, quantified by densitometry and normalized to the corresponding unphosphorylated protein. ${ }^{*} \mathrm{p}<0.05 \mathrm{com}$ pared with the NC group. 


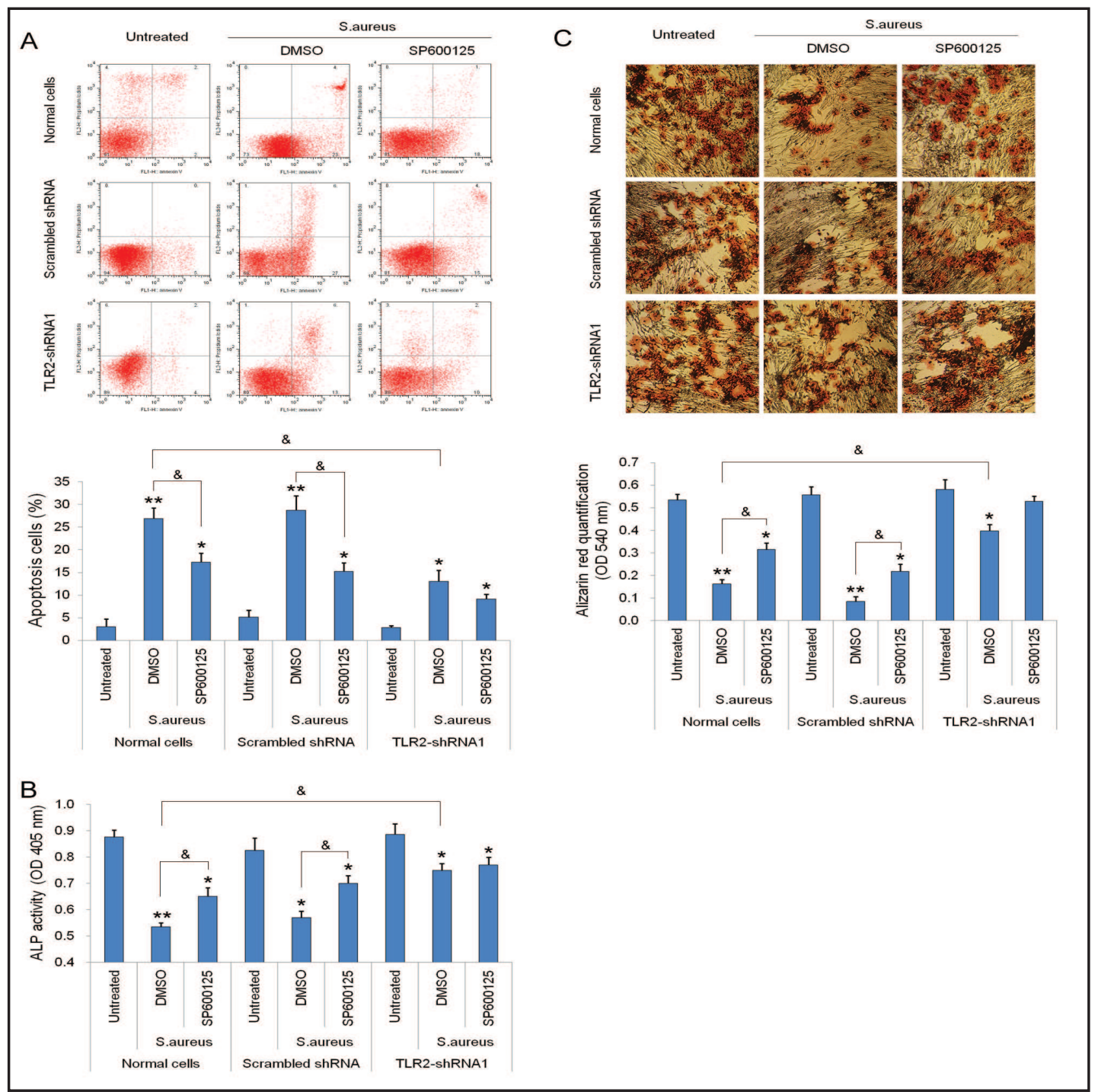

Fig. 5. TLR2 silencing suppressed the effects of $S$. aureus infection on the induction of apoptosis and osteoblast calcification. MC3T3-E1 cells transfected as indicated were pretreated with $25 \mu \mathrm{M}$ of SP600125 or an equal volume of $0.5 \%(\mathrm{v} / \mathrm{v}$ ) DMSO for $1 \mathrm{~h}$. (A) Cells were cultured for $24 \mathrm{~h}$ or infected with S. aureus at $100 \mathrm{MOI}$ and incubated for $24 \mathrm{~h}$. Apoptosis was determined by Annexin V-FITC/PI double staining and flow cytometry. (B) Cells were pretreated as described above and cultured for $7 \mathrm{~d}$ or infected with $S$. aureus at $100 \mathrm{MOI}$ and incubated for $7 \mathrm{~d}$. ALP activity was measured at OD $405 \mathrm{~nm}$. (C) Cells were pretreated as above and cultured for $21 \mathrm{~d}$ or infected with S.aureus at $100 \mathrm{MOI}$ and incubated for $21 \mathrm{~d}$. Representative photomicrographs of Alizarin red stained MC3T3-E1 cells in various groups (200x). Staining was quantified by measuring absorbance at $540 \mathrm{~nm} .{ }^{*} \mathrm{p}<0.05,{ }^{* *} \mathrm{p}<0.01$ compared with the untreated cells. ${ }^{{ }^{*}} \mathrm{p}<0.05$.

\section{Discussion}

The gram-positive bacterium $S$. aureus is a major pathogen associated with a variety of diseases and is the main causative factor in osteomyelitis. Protection from primary staphylococcal infection mainly depends on innate immune responses, in which TLRs play pivotal roles by recognizing pathogen-associated molecular patterns (PAMPs) and activating signaling pathways, and TLR2 plays a key role in the detection of $S$. aureus invasion [24, 25]. In the present study, we investigated the response to $S$. aureus infection in an osteoblastic cell line and examined the underlying mechanisms. Our results showed that inhibition of 


\section{Cellular Physiology and Biochemistry}

Cell Physiol Biochem 2014;34:1890-1900

\begin{tabular}{l|l}
\hline DOI: $10.1159 / 000366387$ & (C) 2014 S. Karger AG, Basel
\end{tabular}

www.karger.com/cpb

Chen et al.: TLR2 Knockdown Attenuates S. Aureus Effects in Osteomyelitis

JNK and ERK abrogated S. aureus induced osteoblast apoptosis, and knockdown of TLR2 attenuated the effects of $S$. aureus on apoptosis and calcium deposition associated with bone remodeling in a manner similar to the inhibition of MAPK signaling, suggesting the existence of a TLR2/MAPK signaling axis in the immune response to bacterial invasion in the bone.

Bone remodeling requires the coordinated activities of osteoblasts and osteoclasts, and bacteria such as $S$. aureus can alter this balance by directly damaging bone and stimulating osteoclastogenesis. Although certain factors such as inflammatory cytokines, which modulate osteoclast formation and activity have been identified [26-28], the exact mechanisms and factors mediating these effects remain unclear. In osteomyelitis, tissue damage is associated with bone cell death, which is important for bone remodeling. In the present study, we showed that $S$. aureus induced apoptosis in an osteoblast cell line in parallel with the upregulation of TLR2 expression and the activation of pro-apoptotic pathways. Furthermore, knockdown of TLR2 attenuated the effects of S. aureus on apoptotic cell death and the $S$. aureus-induced downregulation of markers of calcification, similar to the effect of JNK inhibition. TLRs initiate the innate immune response, in which inflammation is an essential process and is the hallmark of many human diseases [29]. Signal transduction from TLRs induces the expression of many inflammatory-related genes such as cytokines, chemokines, and antimicrobial molecules, and TLR signaling cascades strongly depend on the activities of kinases. In periodontal disease, which is another infection-driven inflammatory bone disease, TLR2 is required for Porphyromonas gingivalis induced inflammatory bone loss [30, 31] and TLR2 deficiency attenuates $P$. gingivalis induced bone loss in mice [32]. These findings are in agreement with the results of the present study and support the role of TLR2 in the inflammatory response to $S$. aureus infection leading to apoptosis and bone remodeling.

The induction of apoptotic cell death by $S$. aureus in osteoblasts is dependent on the detection of microbial products by cell surface receptors and the activation of cellular inflammatory responses. Osteoblasts express members of the TLR family of PAMPs, which recognize microbial pathogens leading to the release of inflammatory cytokines [33, 34]. However, intracellular sensors such as NOD1 and NOD2 also play a role in the recognition of intracellular pathogens [35,36], and the induction of osteoblast apoptosis requires the cooperative action of cell surface and intracellular molecules [35]. The signaling pathways triggered by TLR2 involve the activation of the transcription factor NF- $\kappa B$ and JNK, which initiates the transcription of proinflammatory cytokine genes [37-39]. In the present study, we confirmed the involvement of the JNK pathway in mediating the response of TLR2 to pathogen invasion. However, further research aimed at characterizing the molecules involved and mechanisms underlying osteoblast apoptosis in response to bacterial infection in osteomyelitis is necessary.

MAPKs, which are important in the transmission of extracellular stimuli to the nucleus, play a role in inflammatory responses and cell apoptosis in osteoblasts [40]. We showed that $S$. aureus infection resulted in the phosphorylation of JNK, ERK and c-Jun in MC3T3-E1 cells in parallel with the induction of apoptosis. Furthermore, our results showed that the induction of TLR2 in response to the pathogen was dependent on JNK activity, and the JNKmediated pro-apoptotic effects of $S$. aureus in osteoblasts required the presence of TLR2. These results suggested that the mechanism underlying the induction of apoptosis and osteoblastic differentiation may involve cross-talk between TLR2 and MAPK pathways in osteoblasts. The involvement of a TLR2/JNK pathway in the response to pathogen invasion has been shown in previous studies [41]. Guo et al. showed that LPS, a pro-inflammatory glycolipid component of Gram-negative bacteria, induced apoptosis and inhibited osteoblast differentiation via a mechanism involving the JNK pathway [40]. These authors showed that the LPS mediated activation of ERK and JNK was attenuated by pretreatment with SP600125. Furthermore, SP600125 reversed the LPS induced downregulation of markers of osteoblastic differentiation such as ALP, which supports the present findings showing that the $S$. aureus-induced suppression of ALP activity and osteoblast calcification were reversed by JNK inhibition or TLR2 silencing. An osteomyelitis clinical isolate of $S$. aureus was shown 


\section{Cellular Physiology and Biochemistry}

Cell Physiol Biochem 2014;34:1890-1900

\begin{tabular}{l|l}
\hline DOI: $10.1159 / 000366387$ & (C) 2014 S. Karger AG, Basel
\end{tabular}

www.karger.com/cpb

Chen et al.: TLR2 Knockdown Attenuates S. Aureus Effects in Osteomyelitis

to activate ERK and JNK in a time and dose dependent manner in normal human and mouse osteoblasts in a study that examined the role of MAPK pathways in bacterial invasion in osteoblasts [42]. These authors showed that ERK phosphorylation was dependent on $S$. aureus MOI and it increased at lower MOIs, but decreased at an MOI of 250:1, which was attributed to the induction of cell death. Our findings showing the $S$. aureus activation of ERK in parallel with the induction of apoptosis thus requires further investigation including different infection times and bacterial doses. Nevertheless, these studies support the present findings showing the role of TLR2 as a sensor acting via MAPK pathways in mediating the effect of $S$. aureus on osteoblast apoptosis and osteogenic differentiation in osteomyelitis.

In conclusion, the present study examined the role of TLRs in mediating bacterial recognition and clearance in osteomyelitis. Our results showed that $S$. aureus infection induced TLR2 expression, promoted apoptotic cell death, and activated MAPK pathways in osteoblasts. The effects of bacterial invasion on osteoblast apoptosis and osteogenic differentiation were dependent on TLR2 expression and JNK activation, indicating the involvement of a TLR2/JNK axis in the response of bone to pathogen invasion and suggesting novel targets for the treatment of osteomyelitis.

\section{References}

1 Garzoni C, Kelley WL: Staphylococcus aureus: New evidence for intracellular persistence. Trends Microbiol 2009;17:59-65.

-2 Lew DP, Waldvogel FA: Osteomyelitis. Lancet 2004;364:369-379.

-3 Martin TJ, Sims NA: Osteoclast-derived activity in the coupling of bone formation to resorption. Trends Mol Med 2005;11:76-81.

-4 Widaa A, Claro T, Foster TJ, O'Brien FJ, Kerrigan SW: Staphylococcus aureus protein a plays a critical role in mediating bone destruction and bone loss in osteomyelitis. PLoS One 2012;7:e40586.

-5 Nicolaije C, Koedam M, van Leeuwen JP: Decreased oxygen tension lowers reactive oxygen species and apoptosis and inhibits osteoblast matrix mineralization through changes in early osteoblast differentiation. J Cell Physiol 2012;227:1309-1318.

6 Yadav MC, Simao AM, Narisawa S, Huesa C, McKee MD, Farquharson C, Millan JL: Loss of skeletal mineralization by the simultaneous ablation of phospho1 and alkaline phosphatase function: A unified model of the mechanisms of initiation of skeletal calcification. J Bone Miner Res 2011;26:286-297.

7 Wright JA, Nair SP: Interaction of staphylococci with bone. Int J Med Microbiol 2010;300:193-204.

8 Foster TJ: Colonization and infection of the human host by staphylococci: Adhesion, survival and immune evasion. Vet Dermatol 2009;20:456-470.

-9 Tanaka Y, Nakayamada S, Okada Y: Osteoblasts and osteoclasts in bone remodeling and inflammation. Curr Drug Targets Inflamm Allergy 2005;4:325-328.

10 Claro T, Widaa A, O'Seaghdha M, Miajlovic H, Foster TJ, O'Brien FJ, Kerrigan SW: Staphylococcus aureus protein a binds to osteoblasts and triggers signals that weaken bone in osteomyelitis. PLoS One 2011;6:e18748.

11 Tucker KA, Reilly SS, Leslie CS, Hudson MC: Intracellular staphylococcus aureus induces apoptosis in mouse osteoblasts. FEMS Microbiol Lett 2000;186:151-156.

$\$ 12$ Aderem A, Ulevitch RJ: Toll-like receptors in the induction of the innate immune response. Nature 2000;406:782-787.

13 Kawai T, Akira S: Toll-like receptors and their crosstalk with other innate receptors in infection and immunity. Immunity 2011;34:637-650.

14 Takeda K, Akira S: Toll-like receptors in innate immunity. Int Immunol 2005;17:1-14.

15 Kim S, Karin M: Role of tlr2-dependent inflammation in metastatic progression. Ann N Y Acad Sci 2011;1217:191-206.

16 Takeda K, Kaisho T, Akira S: Toll-like receptors. Annu Rev Immunol 2003;21:335-376.

17 Pearson G, Robinson F, Beers Gibson T, Xu BE, Karandikar M, Berman K, Cobb MH: Mitogen-activated protein (map) kinase pathways: Regulation and physiological functions. Endocr Rev 2001;22:153-183.

18 Cargnello M, Roux PP: Activation and function of the mapks and their substrates, the mapk-activated protein kinases. Microbiol Mol Biol Rev 2011;75:50-83. 


\section{Cellular Physiology \\ Cell Physiol Biochem 2014;34:1890-1900 and Biochemistry

Chen et al.: TLR2 Knockdown Attenuates S. Aureus Effects in Osteomyelitis

19 Johnson GL, Lapadat R: Mitogen-activated protein kinase pathways mediated by erk, jnk, and p38 protein kinases. Science 2002;298:1911-1912.

20 Davis RJ: Signal transduction by the jnk group of map kinases. Cell 2000;103:239-252.

-21 Ventura JJ, Hubner A, Zhang C, Flavell RA, Shokat KM, Davis RJ: Chemical genetic analysis of the time course of signal transduction by jnk. Mol Cell 2006;21:701-710.

22 Cikos S, Bukovska A, Koppel J: Relative quantification of mrna: Comparison of methods currently used for real-time pcr data analysis. BMC Mol Biol 2007;8:113.

23 Saito K, Ohara N, Hotokezaka H, Fukumoto S, Yuasa K, Naito M, Fujiwara T, Nakayama K: Infection-induced up-regulation of the costimulatory molecule $4-1 \mathrm{bb}$ in osteoblastic cells and its inhibitory effect on m-csf/ rankl-induced in vitro osteoclastogenesis. J Biol Chem 2004;279:13555-13563.

24 Shamsuddin N, Kumar A: Tlr2 mediates the innate response of retinal muller glia to staphylococcus aureus. J Immunol 2011;186:7089-7097.

-25 Akira S, Uematsu S, Takeuchi O: Pathogen recognition and innate immunity. Cell 2006;124:783-801.

26 Meghji S, Crean SJ, Hill PA, Sheikh M, Nair SP, Heron K, Henderson B, Mawer EB, Harris M: Surfaceassociated protein from staphylococcus aureus stimulates osteoclastogenesis: Possible role in s. Aureusinduced bone pathology. Br J Rheumatol 1998;37:1095-1101.

-27 Verdrengh M, Carlsten H, Ohlsson C, Tarkowski A: Addition of bisphosphonate to antibiotic and antiinflammatory treatment reduces bone resorption in experimental staphylococcus aureus-induced arthritis. J Orthop Res 2007;25:304-310.

28 Trouillet-Assant S, Gallet M, Nauroy P, Rasigade JP, Flammier S, Parroche P, Marvel J, Ferry T, Vandenesch F, Jurdic P, Laurent F: Dual impact of live staphylococcus aureus on osteoclast lineage leading to increased bone resorption. J Infect Dis 2014

29 Moresco EM, LaVine D, Beutler B: Toll-like receptors. Curr Biol 2011;21:R488-493.

-30 Papadopoulos G, Weinberg EO, Massari P, Gibson FC $3^{\text {rd }}$, Wetzler LM, Morgan EF, Genco CA: Macrophagespecific tlr2 signaling mediates pathogen-induced tnf-dependent inflammatory oral bone loss. J Immunol 2013;190:1148-1157.

-31 Gibson FC, 3rd, Ukai T, Genco CA: Engagement of specific innate immune signaling pathways during porphyromonas gingivalis induced chronic inflammation and atherosclerosis. Front Biosci 2008;13:20412059.

-32 Burns E, Bachrach G, Shapira L, Nussbaum G: Cutting edge: Tlr2 is required for the innate response to porphyromonas gingivalis: Activation leads to bacterial persistence and tlr2 deficiency attenuates induced alveolar bone resorption. J Immunol 2006;177:8296-8300.

-33 Gasper NA, Petty CC, Schrum LW, Marriott I, Bost KL: Bacterium-induced cxcl10 secretion by osteoblasts can be mediated in part through toll-like receptor 4. Infect Immun 2002;70:4075-4082.

-34 Madrazo DR, Tranguch SL, Marriott I: Signaling via toll-like receptor 5 can initiate inflammatory mediator production by murine osteoblasts. Infect Immun 2003;71:5418-5421.

-35 Marriott I, Rati DM, McCall SH, Tranguch SL: Induction of nod1 and nod2 intracellular pattern recognition receptors in murine osteoblasts following bacterial challenge. Infect Immun 2005;73:2967-2973.

-36 Marriott I: Apoptosis-associated uncoupling of bone formation and resorption in osteomyelitis. Front Cell Infect Microbiol 2013;3:101.

-37 Takeuchi 0, Akira S: Toll-like receptors; their physiological role and signal transduction system. Int Immunopharmacol 2001;1:625-635.

- 38 Lin HY, Tang CH, Chen JH, Chuang JY, Huang SM, Tan TW, Lai CH, Lu DY: Peptidoglycan induces interleukin-6 expression through the tlr2 receptor, jnk, c-jun, and ap-1 pathways in microglia. J Cell Physiol 2011;226:1573-1582.

-39 Wang H, Wu Y, Ojcius DM, Yang XF, Zhang C, Ding S, Lin X, Yan J: Leptospiral hemolysins induce proinflammatory cytokines through toll-like receptor 2-and 4-mediated jnk and nf-kappab signaling pathways. PLoS One 2012; 7:e42266.

40 Guo C, Yuan L, Wang JG, Wang F, Yang XK, Zhang FH, Song JL, Ma XY, Cheng Q Song GH: Lipopolysaccharide (lps) induces the apoptosis and inhibits osteoblast differentiation through jnk pathway in mc3t3-e1 cells. Inflammation 2014;37:621-631.

41 Kawai T, Akira S: Tlr signaling. Cell Death Differ 2006;13:816-825.

-42 Ellington JK, Elhofy A, Bost KL, Hudson MC: Involvement of mitogen-activated protein kinase pathways in staphylococcus aureus invasion of normal osteoblasts. Infect Immun 2001;69:5235-5242. 